\title{
The Danish Atopy Database (DAD): Rationale and Methods
}

\author{
Simon Francis Thomsen*, Jakob Mutanu Jungersted, Maja-Lisa Clausen and Tove Agner
}

Department of Dermatology, Bispebjerg Hospital, Copenhagen, Denmark

\begin{abstract}
Atopic dermatitis is a multifactorial chronic disease that poses a great burden for patients and society. In recent decades the prevalence has increased substantially in many countries, notably in Western societies, and the causes for this increase are not completely understood. There are still many unanswered questions regarding atopic dermatitis with respect to aetiology, pathophysiology, co-morbidity as well as subgrouping and treatment of the disease. Establishment of the Danish Atopy Database (DAD), a cohort with ongoing inclusion of outpatients with atopic dermatitis from a tertiary referral centre, allows the study of these aspects of the disease. Herein we present our methodological considerations in regards to establishment of this cohort.
\end{abstract}

Keywords: Atopic dermatitis, database, methodology, outpatient, treatment.

\section{INTRODUCTION}

Atopic dermatitis (AD) is a chronic inflammatory skin disorder that affects around $20 \%$ of the population [1]. The disease is characterized mainly by the presence of dry itchy skin accompanied by chronic or relapsing eczema with an early onset primarily in individuals with a familial history of atopic disorders. In infancy, eczema typically develops on the face and scalp as well as on the extensor aspects of the arms and legs [2]; later in childhood flexural eczema occurs, whereas in adulthood skin changes are more often confined to the face and neck, as well as the hands, although some suffer from more widespread eczema [1]. In adults, hand eczema sometimes is the only symptom, which may however take a chronic course [3]. Widespread skin involvement usually requires various treatments, including support of the psychological and socioeconomic aspects of the disease, and these patients are most often managed in hospital settings. However, in most patients the disease has a favourable prognosis; around $75 \%$ are symptom-free in adolescence and early adulthood.

$\mathrm{AD}$ has a substantial heritable component, and susceptible individuals react to environmental stimuli to develop manifest disease [4]. Immunologically, AD is characterised by activation of $\mathrm{T}$ helper type 2 cells with production of cytokines IL-4, 5 and 13, leading to excessive production of $\mathrm{IgE}$. Another main problem in $\mathrm{AD}$ is a defective skin barrier leading to excessive water loss through the epidermis, and easy access for bacteria and viruses. Identification of mutations in the gene encoding filaggrin in patients with $\mathrm{AD}$ has renewed the interest for the skin barrier [5], and during the latest years much research within $\mathrm{AD}$ has focused on this.

Skin emollients and topical corticosteroids are first line therapy for $\mathrm{AD}$ [6], while topical immunemodulators and

*Address correspondence to this author at the Department of Dermatology, Bispebjerg Hospital, Bispebjerg Bakke 23, DK-2400 Copenhagen NV, Denmark, Tel: +45 26139838; Fax: +45 35313950; E-mail: sft@city.dk
UV-radiation are second line treatments [7]. Recalcitrant disease usually requires treatment with systemic immunosuppressive drugs such as azathioprine, methotrexate, cyclosporine, or mycophenolate mofetil for shorter or longer periods of time [8]. More studies on the effects and side effects of long term treatment of $\mathrm{AD}$ with systemic therapy are needed.

AD poses a great burden both for patients and society and in recent decades the prevalence has increased substantially in many countries, notably in Western societies. Although some countries have witnessed a slight decrease in prevalence in very recent years the disease is continuingly on the rise, presently in many developing countries [9]. The causes for this increase in prevalence are not completely understood and as such there are still many unanswered questions regarding $\mathrm{AD}$.

Establishment of the Danish Atopy Database (DAD), a cohort with ongoing inclusion of outpatients with $A D$, allows the study of various aspects of the disease. Particularly, this cohort will provide the basis for studying the aetiology, natural history and management of $\mathrm{AD}$. The database also provides possibility for long term follow-up of patients on systemic therapy. Herein we present our methodological considerations in regards to establishment of this cohort.

\section{METHODS}

\section{Recruitment of Patients}

From January $1^{\text {st }} 2012$ onwards all outpatients with AD referred to the Department of Dermatology, Bispebjerg Hospital, University of Copenhagen, Denmark will be included in the database. This department is a tertiary referral centre that manages around 500 patients with $\mathrm{AD}$ at the time. The yearly referral rate is around 150 new patients. Consequently, the database will allocate around 150 patients each year and will cover all ages of patients with $\mathrm{AD}$; there are no formal exclusion criteria. However, in order to qualify for inclusion in the database, patients must fulfil the modified 
Table 1. Diagnostic Criteria for Atopic Dermatitis in the Danish Atopy Database

\begin{tabular}{|l|}
\hline Essential Features \\
\hline Itch \\
\hline Eczema with typical morphology and age-specific pattern \\
\hline Important Features \\
\hline Early age of onset \\
\hline Atopy (personal or family history) \\
\hline Dry skin \\
\hline Associated Features \\
\hline Atypical vascular response (i.e. facial pallor, white dermographism) \\
\hline Keratosis pilaris, palmar hyperlinearity, ichtyosis \\
\hline Ocular and periorbital changes \\
\hline Other regional findings (e.g. perioral and periauricular lesions) \\
\hline Perifollicular accentuation, lichenification and excoriations \\
\hline
\end{tabular}

Modified from American Academy of Dermatology (2004) [10].

Hanifin and Rajka criteria [10] as judged by the examining physician (Table 1). It will be possible to later expand the database to include also newly admitted inpatients and also patients managed in other Danish hospitals.

Registration of the patients in the database, as well as all patient-related procedures and methods used are reported to the Data Protection Agency (number BBH-2011-22) and the Scientific Ethics Committee of the Capital Region of Copenhagen (number H-3-2012-FSP6).

\section{Clinical Assessment}

The appearance and severity of the eczema will be determined by the SCORAD evaluation method [11], which assigns a severity score between 0 and 103 points to the patient based on the area of skin involvement, the severity and morphology of the individual lesions and on the subjective discomfort reported by the patient.

\section{Questionnaires}

The quality of life of the patients will be evaluated based on the Dermatology Life Quality Index (DLQI). Patients above 16 years of age will be asked to fill out the adult version of the Danish translation of the DLQI [12], whereas patients below this age will be asked to fill out the childhood DLQI [13]. The DLQI scoring system is a dermatologyspecific quality of life instrument. It is a 10 -question validated questionnaire and is calculated by summing the score of each question resulting in a maximum of 30 and a minimum of 0 points. The higher the score, the more the quality of life is impaired.

Furthermore, each patient will be asked to fill out a general questionnaire concerning current and past symptoms of $\mathrm{AD}$, medications used, and questions regarding the presence of other atopic disorders; asthma, hay fever, and food allergy, as well as questions about smoking, drinking habits and socioeconomic characteristics. A shortened version of the questionnaire will be given to patients below 16 years of age, and for this group the questionnaire may be filled out with the help from parents or other grown-ups (not hospital staff).

\section{Laboratory Tests}

Blood samples will include complete blood count, total $\mathrm{IgE}$, electrolytes, and kidney- and liver function. Genomic DNA will be extracted and typed for three common variants (R501X, 2282del4 and R2447X) in the filaggrin gene. For future analyses, additional serum and whole blood will be stored at -80 degrees. For patients who do not accept blood samples DNA-samples from the buccal mucosa will be used for assessment of filaggrin gene variants.

In adult patients skin prick tests will be performed with standard dilutions of ten common aeroallergens (birch, grass, mugwort, horse, dog, cat, house dust mite (Dermatophagoides pter and Dermatophagoides far), and mould (Alternaria and Cladosporium) and eight common food allergens (milk, egg, peanut, soy, wheat, oat, hazelnut, and cod) (Soluprick $\mathrm{SQ}^{\mathbb{B}}$ system, ALK Abelló, Denmark). Children below three years of age will be tested with a shorter panel. Reactions will be read after $15 \mathrm{~min}$. A positive test result is defined as a positive reaction to at least one of the allergens. The reaction to each of the allergens is regarded as positive if the mean wheal diameter $[(\mathrm{d} 1+\mathrm{d} 2) \times 1 / 2]$ is at least $3 \mathrm{~mm}$. The participants will be requested to discontinue medications that contain antihistamine at least three days before skin testing. Additional aimed prick testing will be performed (e.g., latex for patients working with gloves, and chlorhexidine gluconate for patients working in the health care sector). Patch testing is traditionally a part of the allergy-work up in adult patients with $\mathrm{AD}$, and the result of patch testing is registered in another, corresponding database.

\section{Follow-Up}

Follow-up visits are planned after two weeks and again after three months. At follow-up visits SCORAD and DLQI are recorded. Medication during the last period/since last visit will be registered. For patients with severe disease and/or on systemic medications, follow-up will be scheduled every six to twelve weeks. Long term follow-up data will be available as these patients will continue as outpatients usually for several years (Table 2).

\section{CONCLUDING REMARKS}

Clinical databases have before been used with success in regards to $\mathrm{AD}[14,15]$. Notably, cohorts of hospital-based patients offer advantages (or at least different possibilities) over random population samples traditionally used in epidemiological research, since the included patients are often well-characterised and have been evaluated by specialist doctors. In Denmark we have complete registration of the population through the Civil Registration System, which enables cross-linking of clinical databases with disease registries, registries of imbursement of prescription drugs, and sociodemographic registries [16]. As the DAD advances it will provide a basis for clinical, epidemiological and genetic research in relation to $\mathrm{AD}$. The possibility for follow-up, which includes objective evaluation of disease severity as well as evaluation of health-related quality of life, will en- 
Table 2. Patient Examination Plan for the Danish Atopy Database

\begin{tabular}{|c|}
\hline Baseline Data \\
\hline Clinical Examination \\
SCORAD \\
\hline Questionnaires \\
DLQI \\
General questionnaire (symptoms, medications, comorbidities, \\
socioeconomic characteristics) \\
\hline Paraclinical Tests \\
Blood tests (complete blood count, total IgE, electrolytes, and \\
kidney- and liver function) \\
Filaggrin gene variants \\
Skin prick test (food- and aeroallergens) \\
\hline Optional \\
Patch Test \\
\hline Follow-Up Data \\
\hline Clinical Examination \\
\hline SCORAD \\
\hline Questionnaires \\
\hline DLQI \\
\hline Medications \\
\hline
\end{tabular}

able us to detect effects and side effects of long term systemic treatment of AD.

\section{CONFLICT OF INTEREST}

The authors confirm that this article content has no conflicts of interest.

\section{ACKNOWLEDGEMENTS}

Declared none.

\section{REFERENCES}

[1] Williams HC. Clinical practice. Atopic dermatitis. N Engl J Med 2005; 352: 2314-24.
[2] Halkjær LB, Loland L, Buchvald F, et al. Development of atopic dermatitis during the first 3 years of life. Arch Dermatol 2006; 142: 561-66.

[3] Rystedt I. Hand eczema and long-term prognosis in atopic dermatitis. Acta Derm Venereol Suppl (Stockh) 1985; 117: 1-59.

[4] Thomsen SF, Ulrik CS, Kyvik KO, et al. Importance of genetic factors in the etiology of atopic dermatitis: a twin study. Allergy Asthma Proc 2007; 28: 535-9.

[5] Palmer CN, Irvine AD, Terron-Kwiatkowski A, et al. Common loss-of-function variants of the epidermal barrier protein filaggrin are a major predisposing factor for atopic dermatitis. Nat Genet 2006; 38: 441-6.

[6] Darsow U, Wollenberg A, Simon D, et al. European Task Force on Atopic Dermatitis/EADV Eczema Task Force. ETFAD/EADV eczema task force 2009 position paper on diagnosis and treatment of atopic dermatitis. J Eur Acad Dermatol Venereol 2010; 24: 317-28.

[7] El-Batawy MM, Bosseila MA, Mashaly HM, Hafez VS. Topical calcineurin inhibitors in atopic dermatitis: a systematic review and meta-analysis. J Dermatol Sci 2009; 54: 76-87.

[8] Schram ME, Roekevisch E, Leeflang MM, Bos JD, Schmitt J, Spuls PI. A randomized trial of methotrexate versus azathioprine for severe atopic eczema. J Allergy Clin Immunol 2011; 128: 3539.

[9] Asher MI, Montefort S, Björkstén B, et al. ISAAC Phase Three Study Group. Worldwide time trends in the prevalence of symptoms of asthma, allergic rhinoconjunctivitis, and eczema in childhood: ISAAC Phases One and Three repeat multicountry crosssectional surveys. Lancet 2006; 368: 733-43.

[10] Hanifin JM, Cooper KD, Ho VC, et al. Guidelines of care for atopic dermatitis, developed in accordance with the American Academy of Dermatology (AAD)/American Academy of Dermatology Association "Administrative Regulations for EvidenceBased Clinical Practice Guidelines". J Am Acad Dermatol 2004; 50: 391-404.

[11] European Task Force on Atopic Dermatitis. Severity scoring of atopic dermatitis: the SCORAD Index. Dermatolgy 1993; 186: 2331.

[12] Finlay AY, Khan GK. Dermatology Life Quality Index (DLQI)-a simple practical measure for routine clinical use. Clin Exp Dermatol 1994; 19: 210-6.

[13] Lewis-Jones MS, Finlay AY. The Children's Dermatology Life Quality Index (CDLQI): initial validation and practical use. Br J Dermatol 1995; 132: 942-9.

[14] de Benedictis FM, Franceschini F, Hill D, et al. EPAAC Study Group. The allergic sensitization in infants with atopic eczema from different countries. Allergy 2009; 64: 295-303.

[15] Kjaer HF, Eller E, Høst A, Andersen KE, Bindslev-Jensen C. The prevalence of allergic diseases in an unselected group of 6-year-old children. The DARC birth cohort study. Pediatr Allergy Immunol 2008; 19: 737-45.

[16] Pedersen CB. The Danish Cevil Registration System. Scan J Public Health $2011 ; 39: 22-5$.

(C) Thomsen et al.; Licensee Bentham Open.

This is an open access article licensed under the terms of the Creative Commons Attribution Non-Commercial License (http://creativecommons.org/licenses/by-nc/3.0/) which permits unrestricted, non-commercial use, distribution and reproduction in any medium, provided the work is properly cited. 